\title{
Strain-level typing and identification of bacteria - a novel approach for SERS active plasmonic nanostructures
}

\author{
Evelin Witkowska $^{1} \cdot$ Dorota Korsak $^{2} \cdot$ Aneta Kowalska $^{1} \cdot$ Anna Janeczek $^{1} \cdot$ Agnieszka Kamińska $^{1}$
}

Received: 14 March 2018 / Revised: 16 April 2018 / Accepted: 18 May 2018 / Published online: 16 June 2018

(C) The Author(s) 2018

\begin{abstract}
One of the potential applications of surface-enhanced Raman spectroscopy (SERS) is the detection of biological compounds and microorganisms. Here we demonstrate that SERS coupled with principal component analysis (PCA) serves as a perfect method for determining the taxonomic affiliation of bacteria at the strain level. We demonstrate for the first time that it is possible to distinguish different genoserogroups within a single species, Listeria monocytogenes, which is one of the most virulent foodborne pathogens and in some cases contact with which may be fatal. We also postulate that it is possible to detect additional proteins in the $L$. monocytogenes cell envelope, which provide resistance to benzalkonium chloride and cadmium. A better understanding of this infectious agent could help in selecting the appropriate pharmaceutical product for enhanced treatment.
\end{abstract}

Keywords Listeria monocytogenes $\cdot$ SERS $\cdot$ Bacteria detection $\cdot$ Bacteria identification $\cdot$ Strain level discrimination $\cdot b c r A B C \cdot$ $\mathrm{BcrB} \cdot \mathrm{BcrC} \cdot \mathrm{CadA} 1 \cdot \mathrm{CadA} 2 \cdot \mathrm{PCA}$

\section{Introduction}

Surface-enhanced Raman scattering (SERS) is a technique in which a Raman signal is amplified by several orders of magnitude because of the electromagnetic interaction of light with metal nanostructures $[1,2]$. This technique may be applied in numerous fields of science and life, for instance in the detection and identification of chemical compounds, e.g., poisons, narcotic substances [3], or biological substances, e.g., DNA [4], viruses [5], cancer cells [6]. SERS also provides an opportunity to obtain a spectral fingerprint of different bacterial species, including foodborne species, for instance Listeria

Electronic supplementary material The online version of this article (https://doi.org/10.1007/s00216-018-1153-0) contains supplementary material, which is available to authorized users.

Evelin Witkowska ewitkowska@ichf.edu.pl

Agnieszka Kamińska akamin@ichf.edu.pl

1 Institute of Physical Chemistry, Polish Academy of Sciences, Kasprzaka 44/52, 01-224 Warsaw, Poland

2 Faculty of Biology, Institute of Microbiology, Department of Applied Microbiology, University of Warsaw, Miecznikowa 1, 02-096 Warsaw, Poland monocytogenes [7-9]. For this reason, over the last decade interest in SERS applied to bacteria has rapidly increased [10-12]. This interest is associated with the high sensitivity of the SERS technique and increasing number of bacterial strains dangerous for humans. Moreover, the SERS method enables the detection of even a single bacterium in an analyzed sample [13], making the method more reliable.

Current SERS methods of bacteria detection are performed mainly at the species level. Such experiments are important, e.g., in the case of the detection of Salmonella spp., Cronobacter spp. or Listeria monocytogenes in food samples. These bacteria are listed in Commission Regulation (EC) No. 2073/2005 on microbiological criteria for foodstuffs and were successfully detected via the SERS method from different food matrices [14]. It was also proven that SERS discrimination of two bacterial species belonging to one genus ( $L$. monocytogenes and L. ivanovii) is possible [14]. However, bacteria identification at the strain level is also an important issue as some strains, even within the same species, may be very virulent and pathogenic for humans while others are not. Differentiation between these two groups, pathogenic and non-pathogenic, is crucial in clinical microbiology and in medical and pharmaceutical treatment. Strain level identification is important not only in the matter of determining whether a patient should be prescribed an antibiotic, but also in terms of selecting the appropriate drug (e.g., when a specific 
bacterial strain is resistant to a particular antibiotic). One of the first SERS-based bacteria identification at this level was carried out by Walter et al. [15], who showed that SERS spectra of various Escherichia coli strains differ in the intensity of two bands located at 731 and $1331 \mathrm{~cm}^{-1}$. The identification of different strains belonging to single bacterial species was performed also for Vibrio parahemolyticus [16]. Additionally, it was shown that SERS-based strain level identification is suitable for differentiation of E. coli, Klebsiella pneumoniae, Staphylococcus saprophyticus, and Enterococcus faecalis because of the differences in their antibiotic susceptibility profile [17]. In this paper, we demonstrate that SERS coupled with PCA (principal component analysis) is also suitable for discrimination of L. monocytogenes - it allows the identification of $L$. monocytogenes at the genoserotype level and the detection of some membrane proteins within a single $L$. monocytogens genoserogroup.

L. monocytogenes, one out of 17 species qualified to Listeria genus, is an important foodborne pathogen [18] that can cause serious human infections, such as bacteremia and central nervous system infections, primarily in neonates and immunocompromised adults. It can also cause perinatal infections that may result e.g., in abortions [19]. This organism is one of the most important causes of death from foodborne infections in industrialized countries [20, 21]. Human disease cases and outbreaks caused by this organism have a considerable economic impact on society and the food industry [22]. The main route of infection is through the ingestion of contaminated food products [23], as L. monocytogenes can persist in food processing environments [24-26].

In this study, we demonstrate the possibility of distinguishing $L$. monocytogenes bacteria at strain level by the SERS method. More specifically, we prove that it is possible to differentiate $L$. monocytogenes strains belonging to: (1) different genoserogroups, and (2) a single genoserogroup. The differences in the first case are based on the variance in cell surface antigens, and in the second case, on the presence of additional proteins in the bacterial cell envelope, e.g., CadA1, CadA2 (proteins determining resistance to $\mathrm{Cd}^{2+}$, encoded by cadA1 and cadA2 genes, respectively), BcrB and $\mathrm{BcrC}$ (proteins determining resistance to benzalkonium chloride, encoded by $b c r A B C$ gene). These changes are expressed in the SERS spectrum. Further development of this method may serve clinical laboratories to define whether the analyzed bacterium is able to contaminate food samples/ disinfectants and thus whether it is dangerous for humans.

\section{Materials and methods}

Preparation of the Ag-Au bimetallic SERS substrate The AgAu bimetallic substrate was synthesized according to slightly modified, previously published procedures [27].
In order to obtain the Ag-Au SERS substrates, silver discs (Ø $=10 \mathrm{~mm}, \mathrm{H}=5 \mathrm{~mm}$ ) were mechanically polished with $\mathrm{Al}_{2} \mathrm{O}_{3}$ slurries, first with the particle size of $0.5 \mathrm{~mm}$, and second, with $0.3 \mathrm{~mm}$. After polishing, the silver discs were rinsed with $70 \% \mathrm{C}_{2} \mathrm{H}_{5} \mathrm{OH}$ solution. Then, in order to remove the adsorbed $\mathrm{Al}_{2} \mathrm{O}_{3}$ particles and other possible contaminations, the discs were sonicated for $10 \mathrm{~min}$ in $70 \% \mathrm{C}_{2} \mathrm{H}_{5} \mathrm{OH}$ solution. Subsequently, the Ag discs were rinsed with Millipore water and sonicated for $10 \mathrm{~min}$ in Millipore water. The sonication process was then repeated with a new portion of Millipore water. Next, the discs were electrochemically roughened (oxidation/reduction cycles, ORC) in the electrochemical cell filled with $0.1 \mathrm{M} \mathrm{KCl}$ solution. The three ORCs were applied $(0.5 \mathrm{~V}$ and -0.5 , both for $40 \mathrm{~s} ; 0.5 \mathrm{~V}$ and -0.5 , both for $15 \mathrm{~s} ; 0.5 \mathrm{~V}$ for $15 \mathrm{~s}$ and -0.5 for $30 \mathrm{~s}$ ). In the end the reduction potential of $-0.4 \mathrm{~V}$ was applied for $300 \mathrm{~s}$. After electrochemical roughening the discs were washed in Millipore water and dried.

In order to deposit gold nanostructures onto the roughened surface of the silver discs, the electrochemical cell was first filled with a solution of $0.4 \mathrm{mM} \mathrm{HAuCl}_{4}$ in $0.1 \mathrm{M} \mathrm{HClO}_{4}$ and then the potential of $5 \mathrm{mV}$ was applied for $200 \mathrm{~s}$. Next, the Ag-Au bimetallic SERS substrates obtained as described above were rinsed with Millipore water, dried, and placed in desiccator.

\section{Raman spectroscopy and surface-enhanced raman spectros-} copy In the SERS measurements we used Ag-Au bimetallic SERS substrates onto which the bacterial samples were placed. In order to perform SERS measurements, a Renishaw inVia Raman system equipped with a diode laser with wavelength of $785 \mathrm{~nm}$ was used. The laser light was passed through a line filter and focused on a sample mounted on an $\mathrm{X}-\mathrm{Y}-\mathrm{Z}$ translation stage with a $50 \times$ microscope objective (Leica, NA $=0.25$ ). The microscope was equipped with 1200 grooves per mm grating, cutoff optical filters, and a 1024 $\times 256$ pixel Peltier-cooled RenCam CCD detector, which allowed registering the Stokes part of Raman spectra with 5$6 \mathrm{~cm}^{-1}$ spectral resolution and $2 \mathrm{~cm}^{-1}$ wavenumber accuracy. The laser beam diameter, defined as twice the radius of the circle encompassing the area with $86 \%$ of the total power, was about $2.3 \mu \mathrm{m}$; approximately the same values were obtained from an experimentally obtained laser spot image and from the theoretical formula $(4 \lambda \mathrm{f} / \pi \mathrm{D})$. The experiments were performed under ambient conditions using a back-scattering geometry of $0.5 \mathrm{~mW}$ power at the sample.

The SERS spectra were recorded immediately after placing the analyzed sample onto the SERS substrate. All bacteria were at the same growth stage at the time of sample preparation. The SERS spectra were collected from 25 different points for each sample in mapping mode $(20 \times 40 \mu \mathrm{m})$. The recording of SERS spectra was completed after $\sim 30 \mathrm{~min}$ from placing the sample on the Ag-Au substrate. The spectra were processed with the Wire3 software provided by Renishaw. 
Bacterial strains $L$. monocytogenes strains: $475 / 05,43 / 04,06 /$ 09/s, 2082/03, 06/09, 02/07, 82/04, 16/09, and 01/07 were obtained from the Department of Applied Microbiology, University of Warsaw, Poland.

The samples were collected from large retail outlets, smaller units, and food-producing factories over a $7 \mathrm{y}$ period - from 2004 to 2010. Samples were collected in five cities in central and north-east areas of Poland. All food samples were transported to the laboratories inside portable insulated cold boxes, whereas the swabs were moved in sterile tubes. The samples were immediately subjected to microbiological analysis, which was carried out in accredited laboratories. $L$. monocytogenes isolates recovered from different types of food and food-related sources (pork neck, broccoli, cold cuts, smoked salmon, dumplings, raw salad, smoked herring, smoked blue warehou fillets).

The isolates were serotyped by multiplex PCR, according to the procedure 'in-house method: Listeria monocytogenes molecular serotyping' described by the European Union Reference Laboratory for L. monocytogenes ANSES (Maison-Alfort, France) using primers Lmo0737-1 and Lmo0731, Lmo1118-1 and Lmo1118-2, ORF2110-1 and ORF2110-2, ORF2819-1 and ORF2819-2, PRS1 and PRS2, LIP1, and LIP2. The second PCR assay was performed to detect the presence of the flaA gene (primers flaA-F and flaA-R) [28-30]. Differentiation of L. monocytogenes isolates based on PCR reaction is shown on Figs. S1 and S2 (see Electronic Supplementary Material, ESM).

Identification of the two different $\mathrm{cadA}$ determinants involved the use of the primers cadA-Tn5422F and cadATn5422R for cadAl gene, associated with transposon Tn5422, the primers cadA-pLM80F and cadA-pLM80R for cadA2 gene harbored on plasmid pLM80 [31]. Primers p1 and $\mathrm{p} 2$ were used to produce a PCR fragment containing $b c r A B C$ cassette [32]. The names and sequences of the discussed primers used for PCR are listed in Table S1 in the ESM.

$\mathrm{BC}$ (benzalkonium chloride) and cadmium $\left(\mathrm{Cd}^{2+}\right)$ susceptibility of $L$. monocytogenes isolates is a mechanism connected with the resistance of $L$. monocytogenes bacteria to benzalkonium chloride and cadmium, respectively. It was assessed as described previously by Mullapudi et al., 2008 [33]. Strains were considered resistant to BC, cadmium if they yielded confluent growth on Mueller Hinton agar with 5\% horse blood (MH+HB; Oxoid) supplemented with $10 \mu \mathrm{g} / \mathrm{mL}$ of benzalkonium chloride (Sigma Aldrich), $75 \mu \mathrm{g} / \mathrm{mL}$ cadmium chloride (Sigma Aldrich) [33].

The group affiliation of each strain and the presence of bcr $A B C$ cassette, cadAl and cadA2 genes is shown in Table 1 .

Sample preparation The bacterial isolates were cultured on $\mathrm{MH}+\mathrm{HB}$ agar and/or $\mathrm{MH}+\mathrm{HB}$ supplemented with $75 \mu \mathrm{g} / \mathrm{mL}$ anhydrous cadmium chloride in order to be multiplied. The plates were incubated at $37^{\circ} \mathrm{C}$ for $24 \mathrm{~h}$. After incubation, three single colonies were placed via sterile plastic inoculating loop into $50 \mu \mathrm{L}$ of sterile $0.9 \% \mathrm{NaCl}$ solution, mixed and centrifuged for $5 \mathrm{~min}$ at $4000 \mathrm{rpm}$. The centrifugation process in the saline solution was repeated three times to obtain a solution of pure bacterial cells. The bacteria were finally dispersed in 10 $\mu \mathrm{L}$ of sterile $0.9 \% \mathrm{NaCl}$ solution. The mixtures were subsequently placed onto the SERS substrates and measured after $\sim 5$ min with Raman spectrometer. The concept of the entire experiment is presented in Fig. 1 and in Fig. 2.

In order to estimate the amount of colony forming units in one analyzed sample, three bacterial colonies of similar diameters of $\sim 1 \mathrm{~mm}$ were suspended in $1 \mathrm{~mL}$ of saline solution. For this purpose, a serial 10-fold dilution of bacterial suspension was performed. The volume of $100 \mu \mathrm{L}$ of bacterial suspension was plated and after incubation in $37^{\circ} \mathrm{C}$ for $24 \mathrm{~h}$ the bacterial colonies were counted. The obtained concentration of bacterial cells was $5.7 \times 10^{9} / \mathrm{mL}$.

PCA - spectral data analysis The SERS spectra were prepared for principal component analysis (PCA) using a two-step approach. First, using a built-in OPUS software (Bruker Optic GmbH 2012 version) the spectra were smoothed with Savitzky-Golay filter, the background was removed using baseline correction (concave rubber band correction; no. of iterations 10 , no. of baseline points 64), and then the spectra were normalized using a Min-Max normalization. All the data were transferred to the Unscrambler@ software (CAMO software AS, ver. 10.3, Norway), where the PCA was performed.

Data set used in PCA In this study the analysis was performed over the entire spectral region between 500 and $1630 \mathrm{~cm}^{-1}$. For PCA, the following strains were compared (Fig. 1):

- three strains within three genoserogroups, all without cadA1, cadA2, and bcrABC genes (control groups): 02/ 07 (gr IVb), 2082/03 (gr IIc),and 475/05 (gr IIa)

- two strains within two genoserogroups both with cadAl gene: 43/04(gr IIa) and 82/04(gr IVb)

- two strains within two genoserogroups both with cadA2 gene: 06/09 (gr IIc) and 16/09 (gr IVb)

- two strains within two genoserogroups both with cadA2 and $b c r A B C$ genes: 06/09/S (gr IIa) and 01/07 (gr IVb)

- three strains within one genoserogroup: 02/07 (gr IVb) control group, 16/09 (gr IVb) with cadA2 gene, and 01/07 (gr IVb) with $c a d A 2$ and $b c r A B C$ genes

Additionally, we compared, via PCA, strains within a single genoserogroup (Fig. 2):

- grown on MH+HB agar: 02/07 (gr IVb) - control group, 16/09 (gr IVb) with cadA2 gene, and 82/04 (gr IVb) with cadAl gene 
Table 1 The group affiliation of L. monocytogenes strains used in experiments

\begin{tabular}{|c|c|c|c|c|c|c|c|}
\hline Strain & Source of isolation & Genoserogroup* & bcrABC & $\operatorname{cadAl}$ & $\operatorname{cadA2}$ & $\mathrm{BC}^{* * *}$ & $\mathrm{Cd}^{2+* * * *}$ \\
\hline $475 / 05$ & Pork neck & gr IIa & - & - & - & $\square$ & $\square$ \\
\hline $43 / 04$ & Broccoli & gr IIa & - & + & - & $\square$ & घ \\
\hline 06/09/S & Cold cuts & gr IIa & + & - & + & घ & ! \\
\hline $2082 / 03$ & Smoked salmon & gr IIc & - & - & - & $\square$ & $\square$ \\
\hline 06/09 & Dumplings & gr IIc & - & - & + & $\square$ & घ \\
\hline $02 / 07$ & Smoked blue warehou & gr IVb & - & - & - & $\square$ & $\square$ \\
\hline $82 / 04$ & Raw salad & gr IVb & - & + & - & $\square$ & - \\
\hline $16 / 09$ & Dumplings & gr IVb & - & - & + & $\square$ & $\square$ \\
\hline $01 / 07$ & Smoked herring & gr IVb & + & - & + & घ & घ \\
\hline
\end{tabular}

(+) present; (-) absent

* gr IIa - (serotypes 1/2a-3a), gr IIc (serotypes 1/2c-3c), and IVb (serotypes 4b-4d-4e);

** $\mathrm{BC}$ - benzalkonium chloride;

*** $\mathrm{Cd}^{2+}$ - cadmium cation;

$\square$ - sensitive (growth inhibited on MH+HB medium supplemented with $10 \mu \mathrm{g} / \mathrm{ml}$ benzalkonium chloride and/or $75 \mu \mathrm{g} / \mathrm{ml}$ cadmium chloride);

- - resistant (confluent growth on MH+HB medium supplemented with $10 \mu \mathrm{g} / \mathrm{ml}$ benzalkonium chloride and/or $75 \mu \mathrm{g} / \mathrm{mL}$ cadmium chloride)
- $\quad$ grown on $\mathrm{MH}+\mathrm{HB}$ supplemented with $75 \mu \mathrm{g} / \mathrm{mL}$ anhydrous cadmium chloride: 16/09 (gr IVb) with cadA2 gene and 82/04 (gr IVb) with cadAl gene

This additional experiment was performed to check whether the $\operatorname{cadA}$ genes expression would be seen as a change of the SERS spectrum.

\section{Results and discussions}

In this study, Ag-Au bimetallic substrates were used in all SERS experiments. As was shown in our previous work [27], these particular SERS-active substrates display a SERS EF of $10^{7}$, and thus demonstrate the ability to perform detection of low-concentration standard analytes like $p$ - mercaptobenzoic acid or biological samples such as $\mathrm{ABO}$ antigens [34] or bacterial cells [27]. By applying the Ag-Au bimetallic substrate, we combined the characteristic features of both metals: high chemical stability of Au with very high Raman scattering enhancement for Ag. The SERS-active substrate used in this study exhibits, besides a uniformly high enhancement factor, high reproducibility and stability of recorded signals across a single substrate and between different substrates. The morphology of these SERS-active substrates was visualized by scanning electron microscopy (SEM) technique and is presented in Fig. S3 (see ESM). The SEM images of Ag-Au hybrid surfaces covered with individual bacteria cells are presented in Fig. S4A (see ESM).

Bacterial strains belonging to a single species of the Listeria genus differ in the antigenic determinants localized on the cell surface. These variances are the result of the
Fig. 1 Simplified scheme of the experiment, part I. The color of the dot on each sample indicates a specific genoserogroup: blackgroup IIa, yellow- group IIc, and pink- group IVb

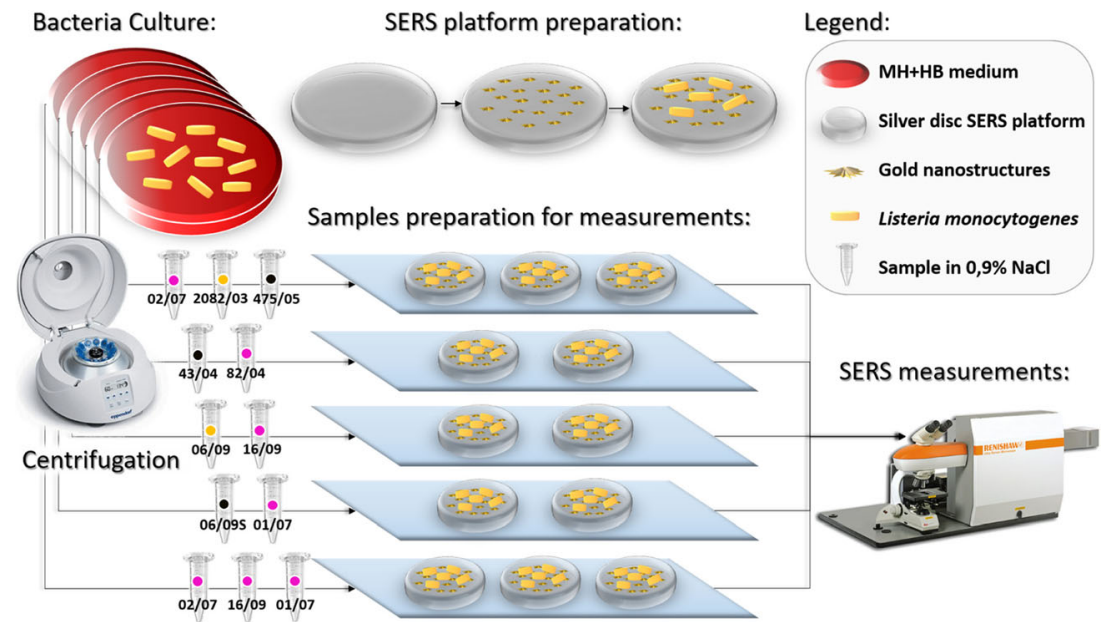


Fig. 2 Simplified scheme of the experiment, part II. The pink color of the dot on each sample indicates the genoserogroup IVb

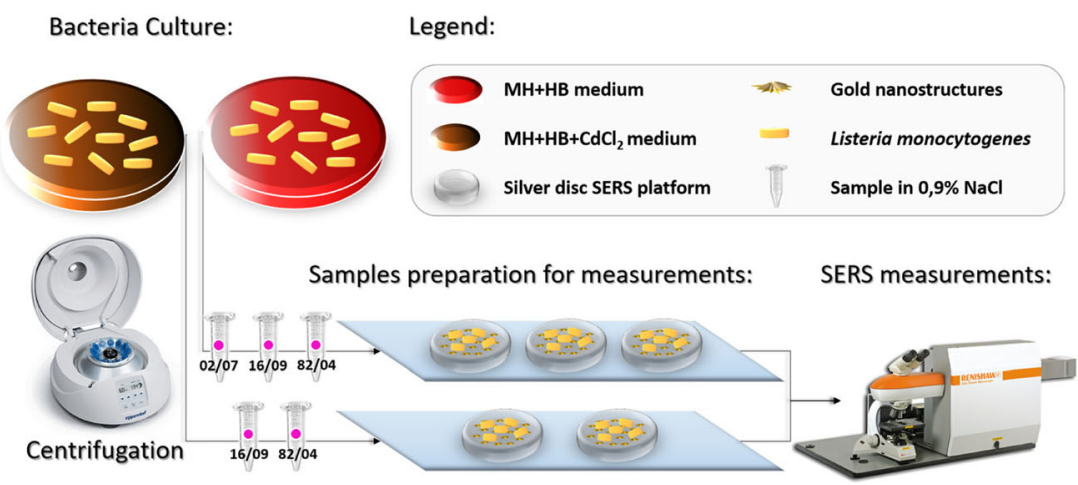

presence of different chemical compounds that enter the structure of bacterial membrane proteins and extracellular organelles. Such dissimilarities between strains may be recognized by serologic typing, which allows for a more detailed analysis of Listeria spp. This typing is determined by the heat-stable somatic antigen $\mathrm{O}$ (15 subtypes: I-XV) and heat-labile ciliary antigen H (4 subtypes: A-D) [35]. Through examination of group-specific Listeria $\mathrm{O}$ and $\mathrm{H}$ antigens, 13 serotypes (i.e., 1/2a, 1/2b, 1/2c, 3a, 3b, 3c, 4a, 4b, 4c, 4d, 4e, 4ab, and 7) have been recognized in $L$. monocytogenes that differ in virulence potential [36]. It has been observed that at least $95 \%$ of $L$. monocytogenes strains isolated from food and $98 \%$ of clinical strains isolated from human listeriosis belong to serotypes $1 /$ $2 \mathrm{a}, 1 / 2 \mathrm{~b}, 1 / 2 \mathrm{c}$, and $4 \mathrm{~b}$ and among these serotypes $1 / 2 \mathrm{a}$ is the most prevalent in food and $4 \mathrm{~b}$ is the most frequently detected serotype from human listeriosis cases [37-39]. This observation shows how important the information about strain of specific bacterium is.

Serotyping has been widely used to characterize $L$. monocytogenes isolates and is important in epidemiological investigations. Rapid and practical molecular serogrouprelated PCR typing of L. monocytogenes has been developed to differentiate the major L. monocytogenes serotypes. As a result, five distinct genoserogroups were distinguished: IIa (1/ $2 \mathrm{a}-3 \mathrm{a})$, IIb (1/2b-3b-7), IIc (1/2c-3c), IVa (4a-4c), IVb (4ab$4 \mathrm{~b}, 4 \mathrm{~d}-4 \mathrm{e})[29,30]$.

In order to distinguish strains of $L$. monocytogenes, we first compared the spectra of three control strains, 475/05, 2082/03, and 02/07 from groups IIa, IIc, and IVb, respectively. As is clear in Figs. 3a, 5a, 6, and 7a, all gathered SERS spectra contain many similar features. In almost every spectrum, bands at ca. 621, 650, 730, 750, 780, 957, 1003, 1033, $1100,1220,1330,1380,1403,1448$, and $1580 \mathrm{~cm}^{-1}$ can be observed. The peaks at $730 \mathrm{~cm}^{-1}$ and $1330 \mathrm{~cm}^{-1}$ are assigned to the adenine part of flavin adenine dinucleotide (FAD). The band at ca. $650 \mathrm{~cm}^{-1}$ comes probably from tyrosine, those at 750 and $780 \mathrm{~cm}^{-1}$ from cytosine or uracil, at $1003 \mathrm{~cm}^{-1}$ from phenylalanine, at $957 \mathrm{~cm}^{-1}$ from $\mathrm{C}=\mathrm{C}$ deformation or $\mathrm{C}-\mathrm{N}$ stretching, and at $1033 \mathrm{~cm}^{-1}$ from $\mathrm{C}-\mathrm{C}$ stretching in phospholipids. The peak at $1100 \mathrm{~cm}^{-1}$ can be assigned to $\mathrm{C}-\mathrm{O}-\mathrm{C}$ stretching in carbohydrates, the band at $1220 \mathrm{~cm}^{-1}$ to thymine, and at $1403 \mathrm{~cm}^{-1}$ to $\mathrm{COO}-$ symmetric stretching. The band at $1448 \mathrm{~cm}^{-1}$ can be linked to $\mathrm{CH}_{2}$ deformation and at $1580 \mathrm{~cm}^{-1}$ to ring stretching in adenine and phenylalanine. The band assignment was based on the research of Luna-Pineda et al., 2007 [40] and Demirel et al., 2009 [41]. Moreover, we measured the reproducibility of the SERS spectra of all analyzed strains of L. monocytogenes and present an example in Fig. S4B (see ESM) for strain 16/09. The presented spectra were recorded in mapping mode within $20 \times 24 \mu \mathrm{m}$ area of SERSactive substrate.

Although all L. monocytogenes strains give mainly the same peaks in SERS spectra, one can still observe differences. These dissimilarities are seen as changes in band intensities and shapes. In Fig. 3a, one can notice changes for all strains, e.g., (1) for the strain 02/07 the present band at about 1112 $\mathrm{cm}^{-1}$ and almost absent bands at $\sim 780,1380$, and $1403 \mathrm{~cm}^{-1}$ in comparison with two other strains; (2) for the strain 2082/03 increased intensity in the $530-570 \mathrm{~cm}^{-1}$ region, as well changed band intensities at about $650,960,1080 \mathrm{~cm}^{-1}$ in comparison with two other strains; and (3) for strain 475/05 an additional band at 822 and $1508 \mathrm{~cm}^{-1}$, changes in the 1240 $1270 \mathrm{~cm}^{-1}$ region, and increased intensity of peaks at 1400 and $1455 \mathrm{~cm}^{-1}$.

Owing to these changes, almost each strain exhibits a characteristic spectrum. The multivariate technique in the form of principal component analysis (PCA) was applied to the obtained SERS data in order to improve the sensitivity of differentiation. The PCA was performed onto preprocessed SERS spectra (smoothened, backgrounded, and normalized) in the entire recorded spectral region (500-1630 $\left.\mathrm{cm}^{-1}\right)$. Examination of the calculated scores and loadings for the most important PCs, as determined from percent variance plots, were used to investigate changes in the spectral features of SERS data. The two principal components, PC-1 and PC-2, were calculated, which together accounted for $92 \%$ of variability and allowed for the differentiation between all studied L. monocytogenes strains. A score plot (Fig. 3b) shows that the spectra could be divided into three groups (clusters) corresponding to $02 / 07$ (blue), 2082/03 (red), and 475/05 (green) strains, from three 
Fig. 3 Average SERS spectra (a), PCA scores (b), and loadings (c) of three L. monocytogenes control strains $(02 / 07,2082 / 03,475 / 05)$, all sensitive to $\mathrm{BC}$ and $\mathrm{Cd}^{2+}$, from three different genoserogroups, filtered from saline solution and recorded on Ag:Au SERS platforms. For all spectra the excitation wavelength was at 785 $\mathrm{nm}$, laser power at $0.5 \mathrm{~mW}$, and acquisition time $45 \mathrm{~s}$. Each SERS spectrum was averaged from at least 25 measurements at different points of the SERS platform
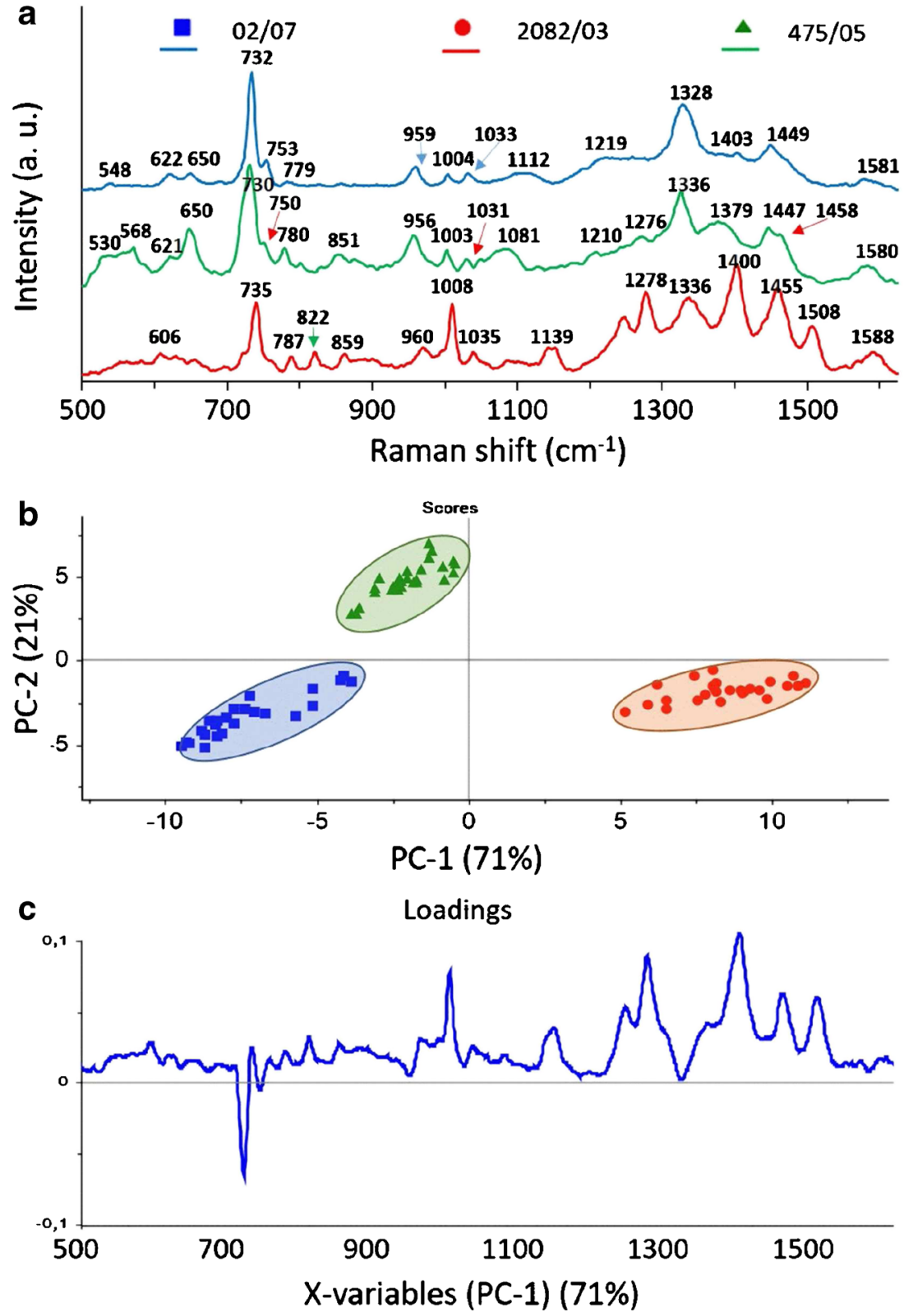

different genoserogroups. Moreover, the loadings of the PCs provide information on the variables (wavenumber of the spectrum) that are important for group separation. Figure $3 \mathrm{c}$ displays the loadings plot of PC1 for the entire wavenumber region. By analyzing these plots, one can indicate the most important diagnostic variables in the analyzed data set. Variables with high loading values are the most important for diagnostic purposes. As can be seen, the wavenumber of $732 \mathrm{~cm}^{-1}$ has the largest weights in the opposite direction. There are other wavenumbers at ca. 1004, 1278, 1400, 1450, $1508 \mathrm{~cm}^{-1}$, which also have an important contribution to PC1 in the same direction. Taking into account the weight of each of these PC1 loadings, it is obvious that in particular five bands at $730,1004,1278,1400$, and $1450 \mathrm{~cm}^{-1}$ are the main contributors to $\mathrm{PC} 1$ and point to the significant changes induced by the variance of surface antigens in bacterial cells. The result of this PCA is consistent with SERS spectra presented in Fig. 3a, which show in these areas intensive SERS bands because of the vibrational $\mathrm{C}-\mathrm{C}$ stretching in phenylalanine $\left(1004 \mathrm{~cm}^{-1}\right)$, the $\mathrm{C}-\mathrm{N}$ stretching mode of the adenine part of flavin adenine dinucleotide $\left(730 \mathrm{~cm}^{-1}\right)$, amide III (1280 $\mathrm{cm}^{-1}$ ), and $\mathrm{CH}_{2}$ deformation (1400 and $1450 \mathrm{~cm}^{-1}$ ).

All these SERS bands originate mainly from the components of the bacterial cell wall and membrane. The tentative assignments of the recorded SERS bands of L. monocytogenes are presented in Table S2 (see ESM). For example, the band at $730 \mathrm{~cm}^{-1}$ corresponds to an in-plane ring breathing mode of adenine or from other adenine-bearing molecules, e.g., flavin 
adenine dinucleotide (FAD), nicotinamide adenine dinucleotide (NAD). The last two molecules are important in the process of cellular respiration taking place in the bacterial cell membrane and demonstrate a close interaction between SERS-active platform and cell wall/ membrane of bacteria. It should likewise be noticed that metabolites of purine degradation may also contribute to the intensity of the band at 730 $\mathrm{cm}^{-1}$ [42]. However, according to Premasiri et al. the band at $1352 \mathrm{~cm}^{-1}$ (not observed in our spectra) represents a metabolic by-product like pyocyanin, a pigment that bacteria produce during their growth. This suggests little to no interference from environmental contaminations and bacterial metabolic products in our recorded spectra. It should be clarified that bands corresponding to these contaminations may also be masked by strong bacterial signals and therefore not affect the discrimination analysis. Moreover, the bands at 1004, 1278,1400 , and $1450 \mathrm{~cm}^{-1}$ correspond to protein vibrational modes and contribute to highest weight in PCA differentiation. This suggests that the spectral differences between the examined strains come mainly from different bacterial envelope proteins.

As genoserotyping is based on differences in surface antigens, it is possible to see the changes in SERS signal during measurements carried out on bacteria strains belonging to different genoserogroups.

In the next step, the comparison of the SERS spectra of strains belonging to different genoserogroups of $L$. monocytogenes, containing cadAl gene (strains $43 / 04$ and 82/04, Fig. 4a), cadA2 gene (strains $16 / 09$ and 06/09, Fig. $4 \mathrm{~b}$ ), or $c a d A 2$ and $b c r A B C$ genes (strains $01 / 07$ and $06 / 09 / \mathrm{S}$, Fig. 4c) was performed. This was done to confirm the results from the previous experiment, which proved the possibility of assigning L. monocytogenes strains to specific genoserogroups. Here, the strains with the same set of resistance genes but from different genoserogroups were matched. This means that the only difference between the compared strains was in the types of surface antigens.

As can be observed in Fig. 4a-c, for each pair of $L$. monocytogenes strains the calculated scores are grouped into two clusters. The obtained PC-1 and PC-2 values yield $84 \%$ of total variance for two L. monocytogenes strains containing cadAl gene (43/04 and 82/04) from IIa and IVb genoserogroups, respectively (Fig. 4a). For the two strains within two genoserogroups both with cadA2 gene, 06/09 (gr IIc) and 16/09 (gr IVb), the calculated PC-1 and PC-2 values were also high and explained the $89 \%$ of the total variance among the studied samples (Fig. 4b). PCA also revealed differentiation between two strains within two genoserogroups both with $c a d A 2$ and $b c r A B C$ genes, 06/09/S (gr IIa) and 01/ 07 (gr IVb) with $66 \%$ accuracy.

These data strongly indicate the possibility of classification among strains from different genoserogroups. This means that the SERS technique is able to distinguish the surface antigen profile of $L$. monocytogenes bacteria from one genoserogroup from bacteria representing other genoserogroups. In many cases the information derived from the cell envelope is sufficient to determine the genoserogroup and strain of a bacterium. Our experiments prove that the SERS signals of bacterial cells come mainly from the cell envelope and molecules located in close proximity to it.

Moreover, we wanted to check whether it is possible to detect SERS spectra changes caused by the presence of the proteins determining resistance to heavy metal $\left(\mathrm{Cd}^{2+}\right)$ and disinfectant $(\mathrm{BC})$. In some bacterial strains there are specific genes whose expression is manifested by the presence of efflux pumps. Such pumps can extrude one definite substrate or a range of compounds out of the bacterial cell, leading to drug resistance [43]. This may refer to quaternary ammonium compounds such as benzalkonium chloride (BC), which are extensively used in the food processing environment and also in health care [44]. One of the known mechanisms leading to BC resistance in L. monocytogenes is connected with the presence of the resistance cassette $b c r A B C$, which is composed of TetR family transcriptional regulator $(b c r A)$ and two SMR genes ( $b c r B$ and $b c r C$ ). SMR protein is a proton-depended multidrug efflux system. This efflux system was first identified on a large, ca $80 \mathrm{~kb}$, plasmid pLM80 [32].

So far it has been demonstrated that the pLM80 plasmid plays a role not only in conferring $\mathrm{BC}$ resistance on particular L. monocytogenes strains, but also in the cadmium $\left(\mathrm{Cd}^{2+}\right)$ resistance of these strains because of the presence of the cadA2 gene [31]. The other cadmium resistance determinant, cadAl, was harbored on the Tn5422 transposon, associated with plasmids of various sizes [45]. The CadA1 and CadA2, which are the $\mathrm{Cd}^{2+}$-ATPases, belong to the $\mathrm{Zn}^{2+} / \mathrm{Cd}^{2+} / \mathrm{Pb}^{2+}$ ATPase bacterial subfamily of $\mathrm{P}_{1 \mathrm{~B}}$-ATPases that ensure detoxification of bacteria [46]. The efflux pump encoded by cadAl and $c a d A 2$ genes helps bacteria to avoid poisoning by $\mathrm{Cd}^{2+}$ and $\mathrm{Zn}^{2+}$. Interestingly, it has been shown that $\mathrm{Cd}^{2+}{ }_{\text {-resistant }}$ isolates that were also resistant to $\mathrm{BC}$ were more likely to harbor cadA2 alone or together with cadA1 than isolates that were $\mathrm{Cd}^{2+}$ resistant but BC susceptible [31].

The sizes of the mentioned efflux pumps are different. CadA1 is composed of 711 amino acids (aa), CadA2 of 705 aa, while BcrB of 106 aa and BcrC of 113 aa. As can be easily calculated, the CadA proteins are more than three times larger than the BC efflux pump system; however, their main parts are located in the cytoplasm. The CadA proteins are composed of eight transmembrane helices. In turn, each SMR protein ( $\mathrm{BcrB}$ and $\mathrm{BcrC}$ ) is composed of four transmembrane $\alpha$ helices [47], giving a final efflux pump composed of eight transmembrane helices. This means that the sizes of the transmembrane parts of these two pumps are more or less the same. This information seems to be crucial for observing these proteins in SERS spectrum with the same probability. 
Fig. 4 PCA of two $L$. monocytogenes strains containing: (a) cadA1 gene (43/04 and 82/04) from different genoserogroups (IIa and IVb); (b) cadA2 gene (16/09 and 06/09) from different genoserogroups (IVb and IIc), and (c) both cadA2 and $b c r A B C$ genes $(01 / 07$ and $06 /$ 09S) from different genoserogroups (IVb and IIa). For all spectra the excitation wavelength was at $785 \mathrm{~nm}$, laser power at $0.5 \mathrm{~mW}$, and acquisition time $45 \mathrm{~s}$. Each SERS spectrum was averaged from at least 25 measurements at different sites of the SERS
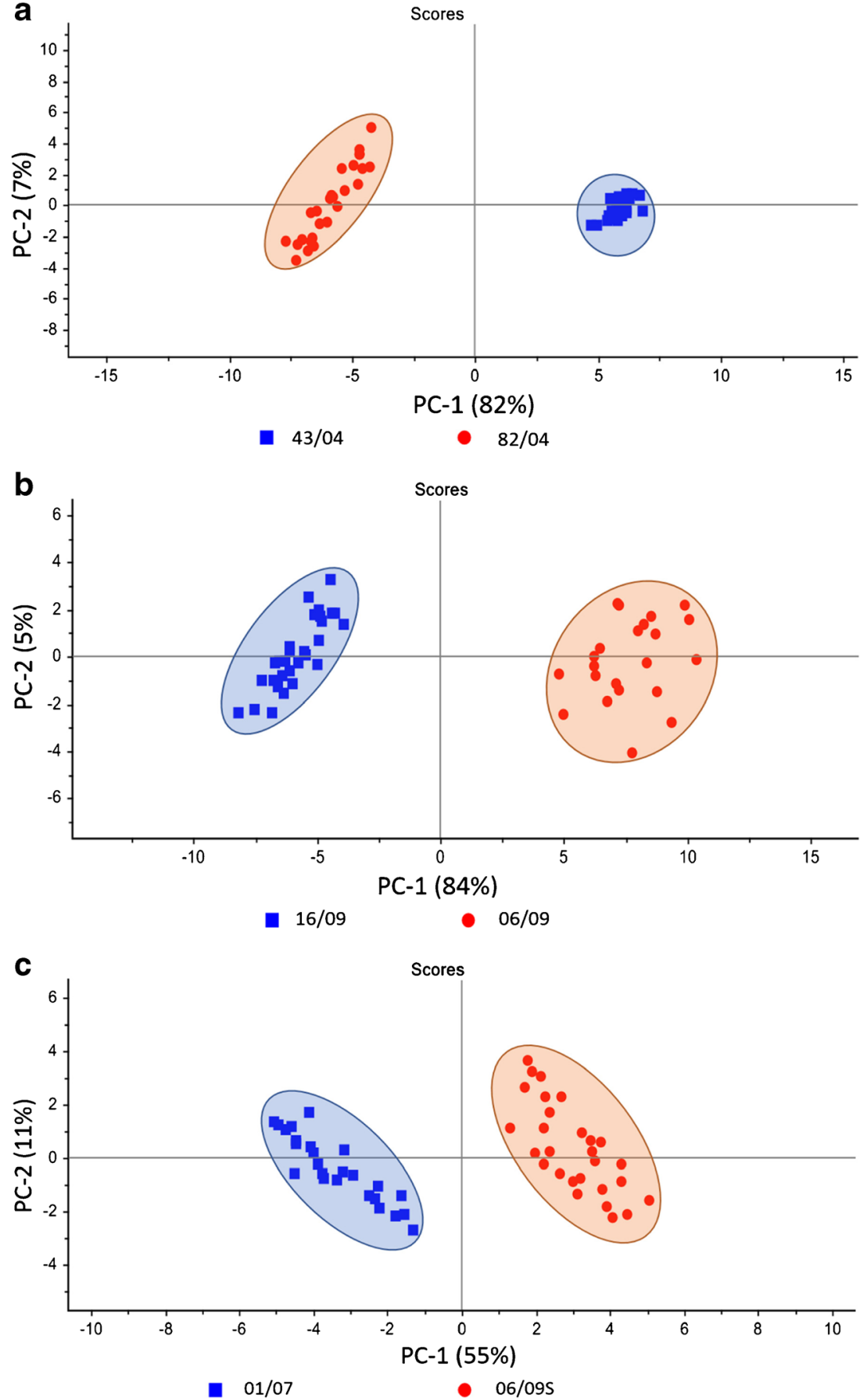

In this work, we compared the control strain 02/07 with a strain containing cadA2 gene (16/09) and a strain containing both $c a d A 2$ and $b c r A B C$ genes (01/07), all from the same genoserogroup ( $\mathrm{IVb})$. It is clear that it is possible to distinguish, with high accuracy, a strain containing bcr $A B C$ cassette from strains without it. The average SERS spectra of three L. monocytogenes strains from one genoserogroup (IVb) exhibit some differences (Fig. 5a). The highest changes can be seen for strain $01 / 07$, in which one can observe a strong decrease in the intensity of the band at $\sim 730 \mathrm{~cm}^{-1}$ and increased intensities of the bands at $1008,1250,1403$, and $1583 \mathrm{~cm}^{-1}$. Strains $16 / 09$ and $02 / 07$ have very similar SERS spectra, but they exhibit a key difference in the band at $753 \mathrm{~cm}^{-1}$, which is absent in the case of strain 16/09 and present in the case of strain 02/07.

As seen in Fig. 5b, the calculated PC-1 and PC-2 values yield $88 \%$ of total variance for these two L. monocytogenes strains with the $b c r A B C$ cassette (red and blue marks) and without it (green marks) and illustrate their excellent differentiation. For better visualization of differentiation, especially 
Fig. 5 Average SERS spectra (a) and PCA (b) of three $L$

monocytogenes strains from one genoserogroup (IVb) filtered from saline solution and recorded on Ag:Au SERS platforms; PCA of two $L$ monocytogenes strains: 16/09 and 02/07 (c). For all spectra, the excitation wavelength was at $785 \mathrm{~nm}$, laser power at $0.5 \mathrm{~mW}$, and acquisition time $45 \mathrm{~s}$. Each SERS spectrum was averaged from at least 25 measurements at different points of the SERS platform
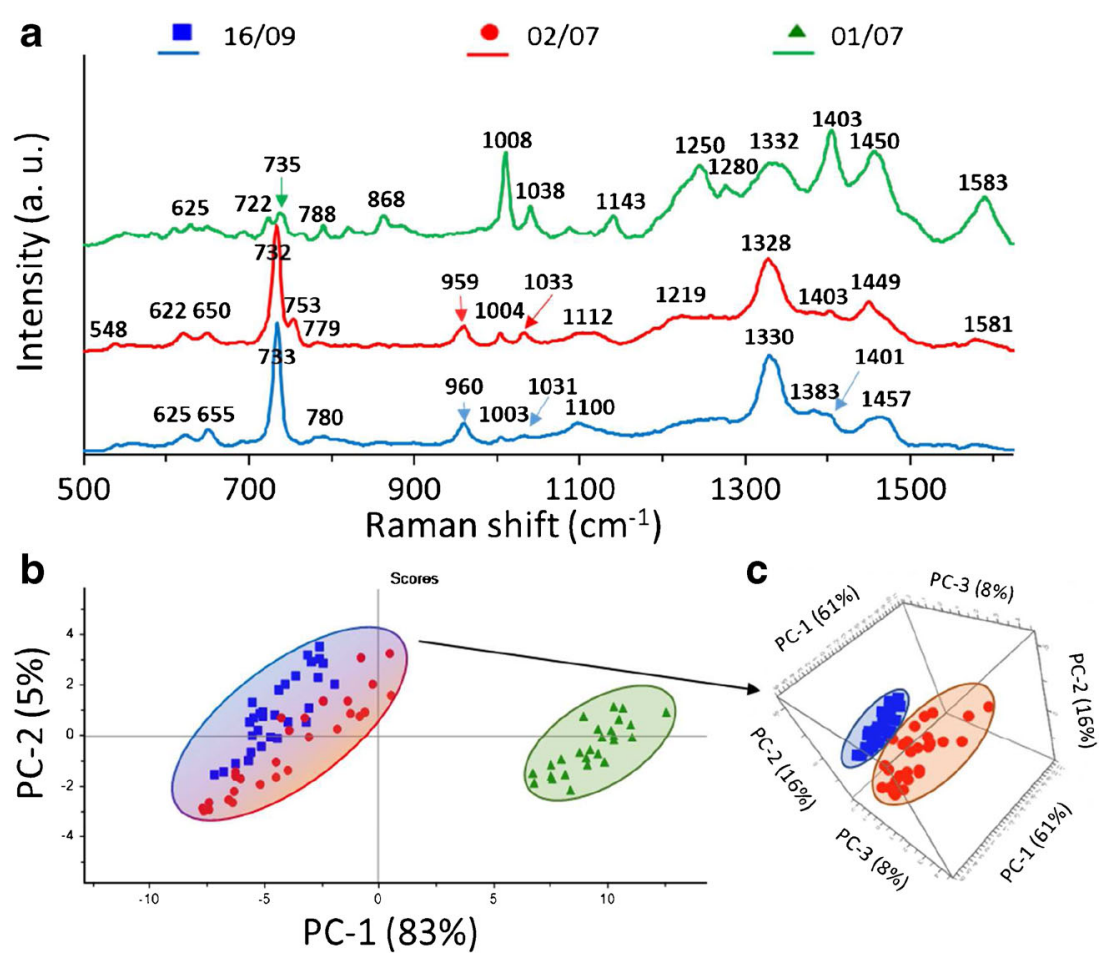

between 16/09 and 02/07 samples, the PCA scores are presented in 3D (Fig. 5c; ESM Figs. S5, S6).

In the next step, we have checked whether the presence of cadA determinants (without bcrABC cassette) affects the SERS spectrum of bacteria. The control strain $(02 / 07)$ with strains containing cadAl (82/04) or cadA2 genes (16/09) have been compared. All strains where from the same genoserogroup (IVb). As one can notice in Fig. 6, the SERS spectra of all studied bacteria look very much alike. The only difference was the small peak located at $\sim 753 \mathrm{~cm}^{-1}$, which was present in the case of strains $02 / 07$ and 82/04 and absent in the case of the strain 16/09. For this reason it was not possible to distinguish these strains with high accuracy via PCA (ESM Fig. S7).

Finally, the same strains as discussed above $(16 / 09,02 / 07$, and 82/04) were applied in new experimental conditions in order to check whether the cadA genes expression would be seen as the change of the SERS spectrum. To perform this approach, the strains 16/09 and 82/04 were grown on $\mathrm{MH}+$ HB broth supplemented with $75 \mu \mathrm{g} / \mathrm{mL}$ anhydrous cadmium chloride (Fig. 2). The obtained data were matched with 02/07 strain grown on $\mathrm{MH}+\mathrm{HB}$ broth without supplementation, as it
Fig. 6 The average SERS spectra of three $L$. monocytogenes strains $(16 / 09,02 / 0$, and 82/04) from one genoserogroup (IVb). For all measurements excitation wavelength was at $785 \mathrm{~nm}$, laser power at $0.5 \mathrm{~mW}$, and acquisition time was $45 \mathrm{~s}$. Each SERS spectrum was averaged from at least 25 measurements at different points of the SERS platform

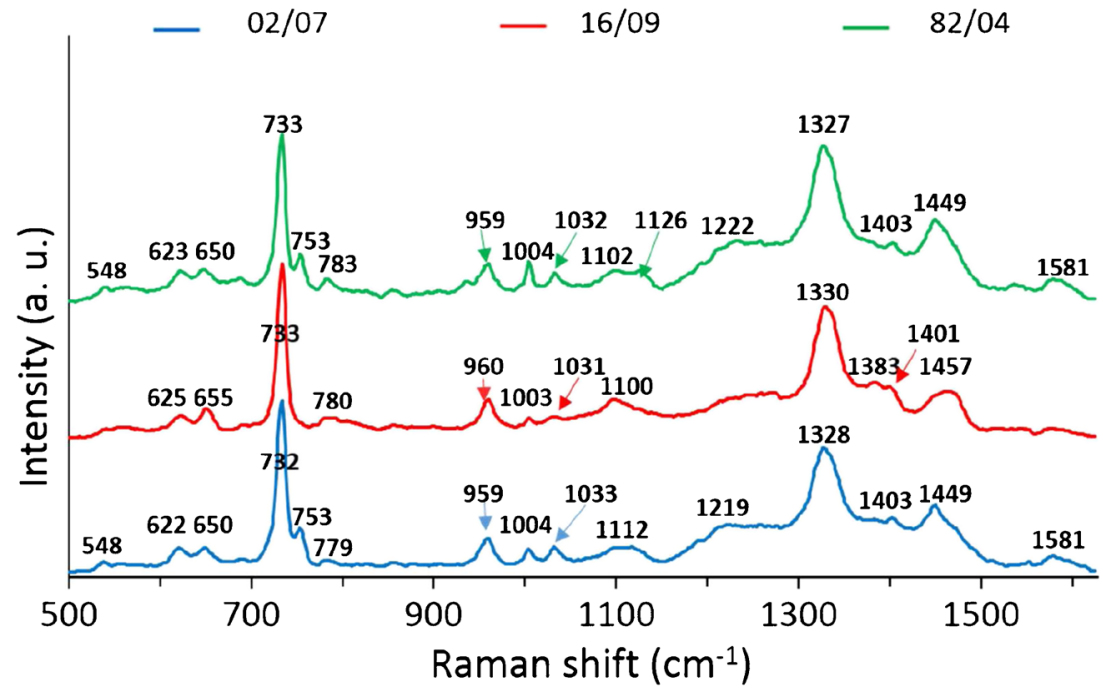


is sensitive to $\mathrm{Cd}^{2+}$ and will not grow on medium supplemented with cadmium chloride. As can be seen in Fig 7a, the averaged SERS spectra of three L. monocytogenes strains look remarkably different. The difference between the strains $02 / 07$ and 16/09 in the form of the absence/presence of the band 753 $\mathrm{cm}^{-1}$ can still be seen. However, the spectrum of the strain 82/ 04 has changed a lot - we can see increased bands intensities at $~ 1221 \mathrm{~cm}, 1453$, and $1583 \mathrm{~cm}^{-1}$. The band at $1221 \mathrm{~cm}^{-1}$ is associated with proteins in cell membrane and also with cytosolic proteins [48]. The band at $1453 \mathrm{~cm}^{-1}$ also originates from protein bands (umbrella mode of methoxyl [4] and C-H bending mode of structural proteins [49]). The bacteria bands at $753 \mathrm{~cm}^{-1}$ (symmetric breathing of tryptophan [50]) and 1583 $\mathrm{cm}^{-1}(\mathrm{C}=\mathrm{C}$ bending mode of phenylalanine [51]) originate from tryptophan and phenylalanine, respectively, two crucial amino acids in the bacterial proteins. This suggests that the observed spectral differences between analyzed strains come mainly from the different bacterial surface proteins.

The resulting PC-1 versus PC-2 scores calculated for the described SERS data give $91 \%$ of total variance (PC-1 plus PC-2). This demonstrates excellent differentiation of these strains with high accuracy. Figure $7 \mathrm{~b}$ presents three separated clusters corresponding to the strains $16 / 09$ (red), 82/04 (green), and 02/07 (blue) from one genoserogroup (IVb) of L. monocytogenes.
It should be highlighted that in Figs. 5 and 7 the obtained scores (in percentage values) of $\mathrm{PC} 1$ and $\mathrm{PC} 2$ are very similar and give together $88 \%$ and $91 \%$ variance, respectively. The main difference concerns the cluster/inter-score distances, which are larger in Fig. 7 and indicate a better distinction among studied samples.

Moreover, the validation of PCA method used for identification of L. monocytogenes at strain level for three food matrices was performed. In the first step, the PCA analysis for three strains, 16/09 (red), 82/04 (green), and 02/07 (blue) from one genoserogroup (IVb) of L. monocytogenes from selected food medium (three food samples were studied and a total 75 SERS spectra were collected; 25 SERS spectra for all studied strains) was applied to build the PCA model. Then the additional data of the test sample [external food sample (smoked salmon) with known strain identified by PCR method] were introduced into this model. The calculated PCA scores are included in Fig. S8 (see ESM) as asterisks. The test sample is located in the clusters of the model PC scores corresponding to particular strain of analyzed species. These results present the analytical potential of SERS technique combined with PCA analysis towards strain level bacteria identification.

In summary, this work demonstrates the possibility of detecting $\mathrm{BC}$ efflux pump in $L$. monocytogenes cell membrane and sheds new light on the opportunity offered by SERS
Fig. 7 The average SERS spectra (a) and PCA (b) of three $L$. monocytogenes strains $(16 / 09$, $02 / 07$, and $82 / 04$ ) from one genoserogroup (IVb). Strains 16/09 and 82/04 were cultured on medium supplemented with $\mathrm{CdCl}_{2}$. For all measurements excitation wavelength was at 785 $\mathrm{nm}$, laser power at $0.5 \mathrm{~mW}$, and acquisition time was $45 \mathrm{~s}$. Each SERS spectrum was averaged from at least 25 measurements at different places of the SERS platform
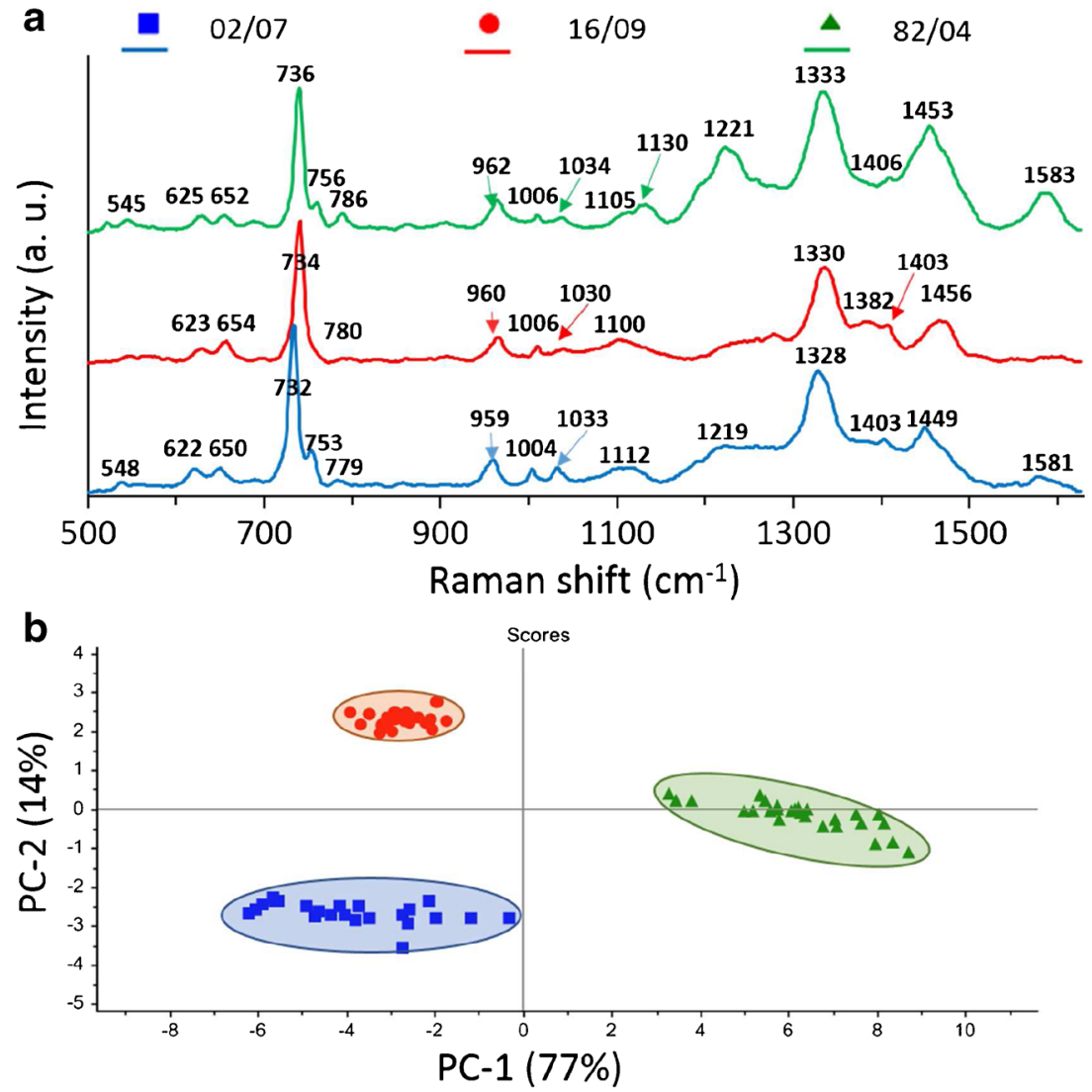
technology in bacteria identification at the strain level. However, the selectivity manifested by the possibility of observing $\mathrm{BC}$ efflux pumps and the lack of opportunity to observe CadA proteins in bacteria grown on $\mathrm{MH}+\mathrm{HB}$ without supplementation was somehow disturbing. Such results, however, could be well explained. It turns out that in spite of genomic proximity of $c a d A 2$ and $b c r A B C$ genes on pLM80, the cassettes mediating resistance to $\mathrm{BC}$ and to $\mathrm{Cd}^{2+}$ are not regulated by the same substrates. As proven previously by Elhanafi et al. in 2010, after the exposure of strains containing $b c r A B C$ cassette, increased bcr $A B C$ transcript levels are observed; however, these transcripts are also detected even in the absence of the disinfectant [32].

Interestingly, such results were not observed for cadA genes. Their expression is induced only in the presence of $\mathrm{Cd}^{2+} \mathrm{Zn}^{2+} \mathrm{Pb}^{2+} \mathrm{Bi}^{3+}$, from which $\mathrm{Cd}^{2+}$ is the most powerful inducer [52]. This is connected with the fact that $\mathrm{Cd}^{2+}$-ATPase from L. monocytogenes can use $\mathrm{Cd}^{2+}$ as a co-substrate [53]. For this reason, the contribution of CadA proteins was seen in the SERS spectrum only in the case when bacteria were grown on medium supplemented with cadmium chloride (compare Figs. 6 and 7).

Previously, it was shown that the dominant molecular species giving their contribution to the SERS spectra of bacteria excited at $785 \mathrm{~nm}$ are the metabolites of purine degradation [42]. However, slight changes of the dominant SERS bands may be caused by the presence of the additional proteins/ enzymes produced by bacterial cells, which can be concluded from the SERS experiments performed with $E$. coli strains. Premasiri et al. claimed that the SERS spectrum of $E$. coli 6757, which has the most different drug resistance profile from the other five measured E. coli strains, has also the most different SERS spectrum [17].

In the present study, some of the investigated bacterial strains were resistant to $\mathrm{BC}$ and cadmium or cadmium alone. The resistance mechanisms were associated with the presence of additional proteins in their cell membrane. Previous experiments showing the possibility of SERS-based bacteria identification did not consider what the molecular resistance mechanism of strains under study was. Hypothetically, this could be the reason for the inability of differentiation of all bacteria strains [17].

\section{Conclusions}

Identification of bacterial strains is very important, especially in the case of disease diagnosis. This in particular applies to strains of bacteria that have acquired resistance to specific compounds, e.g., antibiotics, heavy metals, or disinfectants. The expression of such resistance genes allows the survival of a strain. This article shows that the differentiation between genoserogroups from one bacterial species, L. monocytogenes, by SERS-PCA-based experiment is possible, as the detection of proteins determining resistance to heavy metal $\left(\mathrm{Cd}^{2+}\right)$ and disinfectant (BC). A comparison of the obtained PCA results (the sum of $\mathrm{PC} 1$ and $\mathrm{PC} 2$ ) is shown in Table $\mathrm{S} 3$ (see ESM).

The results shown in this paper indicate that the signal observed during SERS experiments of bacteria cells comes mainly from the cell envelope and molecules located in its close proximity. As long as the expression of some genes is manifested by the presence of specific proteins in the cell membrane and as long as the genoserotyping is based on differences in surface antigens, the changes in SERS signal during measurements carried out on different bacterial strains belonging to a single species will probably be observed. These results demonstrate the rapid identification of bacteria at strain level based on different kinds of surface antigens and resistance genes. The research presented here should open a new path in microbiological diagnostics. In summary, the proposed SERS-PCA-based method of bacteria identification is sensitive, label-free, cost effective, fast, and may be performed using portable Raman equipment. In the future it can become an alternative and robust tool for the identification of pathogens.

Acknowledgments Evelin Witkowska expresses thanks for the financial support from the National Science Center under grant UMO-2016/21/N/ ST4/00910.

Agnieszka Kamińska expresses thanks for the financial support from the National Science Center under grant UMO-2015/17/B/ST4/04128.

\section{Compliance with ethical standards}

Conflict of interest The authors declare that they have no conflict of interests.

Open Access This article is distributed under the terms of the Creative Commons Attribution 4.0 International License (http:// creativecommons.org/licenses/by/4.0/), which permits unrestricted use, distribution, and reproduction in any medium, provided you give appropriate credit to the original author(s) and the source, provide a link to the Creative Commons license, and indicate if changes were made.

\section{References}

1. Kneipp K, Wang Y, Kneipp H, Perelman LT, Itzkan I, Dasari RR, et al. Single molecule detection using surface-enhanced raman scattering (SERS). Phys Rev Lett. 1997;78:1667-70.

2. Smith E, Dent G. Surface-enhanced Raman scattering and surfaceenhanced resonance raman scattering. Modern Raman Spectroscopy - A Practical Approach. Hoboken: Wiley; 2005.

3. Sägmüller B, Schwarze B, Brehm G, Trachta G, Schneider S. Identification of illicit drugs by a combination of liquid chromatography and surface-enhanced Raman scattering spectroscopy. J Mol Struct. 2003;661-662:279-90.

4. Xu L-J, Lei Z-C, Li J, Zong C, Yang CJ, Ren B. Label-free surfaceenhanced Raman spectroscopy detection of DNA with single-base sensitivity. J Am Chem Soc. 2015;137:5149-54. 
5. Shanmukh S, Jones L, Driskell J, Zhao Y, Dluhy R, Tripp RA. Rapid and sensitive detection of respiratory virus molecular signatures using a silver nanorod array SERS substrate. Nano Lett. 2006;6:2630-6.

6. Qian X, Peng XH, Ansari DO, Yin-Goen Q, Chen GZ, Shin DM, et al. In vivo tumor targeting and spectroscopic detection with surfaceenhanced Raman nanoparticle tags. Nat Biotechnol. 2008;26:8390.

7. Liu Y, Chen Y-R, Nou X, Chao K. Potential of surface-enhanced Raman spectroscopy for the rapid identification of Escherichia coli and Listeria monocytogenes cultures on silver colloidal nanoparticles. Appl Spectrosc. 2007;61:824-31.

8. Stambach N, Carr S, Cox C, Voorhees K. Rapid detection of Listeria by bacteriophage amplification and SERS-lateral flow immunochromatography. Viruses. 2015;7:2962.

9. Green GC, Chan ADC, Luo BS, Dan H, Lin M. Identification of Listeria species using a low-cost surface-enhanced Raman scattering system with wavelet-based signal processing. IEEE Trans Instrum Meas. 2009;58:3713-22.

10. Jarvis RM, Goodacre R. Discrimination of bacteria using surfaceenhanced Raman spectroscopy. Anal Chem. 2004;76:40-7.

11. Premasiri WR, Moir DT, Klempner MS, Krieger N, Jones G, Ziegler LD. Characterization of the surface enhanced Raman scattering (SERS) of bacteria. J Phys Chem B. 2005;109:312-20.

12. Kusic D, Kampe B, Ramoji A, Neugebauer U, Rosch P, Popp J. Raman spectroscopic differentiation of planktonic bacteria and biofilms. Anal Bioanal Chem. 2015;407:6803-13.

13. Alexander TA, Pellegrino PM, Gillespie JB. Near-infrared surfaceenhanced-Raman-scattering-mediated detection of single optically trapped bacterial spores. Appl Spectrosc. 2003;57:1340-5.

14. Witkowska E, Korsak D, Kowalska A, Księżopolska-Gocalska M, Niedziółka-Jönsson J, Roźniecka E, et al. Surface-enhanced Raman spectroscopy introduced into the International Standard Organization (ISO) regulations as an alternative method for detection and identification of pathogens in the food industry. Anal Bioanal Chem. 2017:409:1555-67.

15. Walter A, Marz A, Schumacher W, Rosch P, Popp J. Towards a fast, high specific, and reliable discrimination of bacteria on strain level by means of SERS in a microfluidic device. Lab Chip. 2011;11: 1013-21.

16. Xu J, Turner JW, Idso M, Biryukov SV, Rognstad L, Gong H, et al. In situ strain-level detection and identification of vibrio parahaemolyticus using surface-enhanced Raman spectroscopy. Anal Chem. 2013;85:2630-7.

17. Premasiri WR, Chen Y, Williamson PM, Bandarage DC, Pyles C, Ziegler LD. Rapid urinary tract infection diagnostics by surfaceenhanced Raman spectroscopy (SERS): identification and antibiotic susceptibilities. Anal Bioanal Chem. 2017;409:3043-54.

18. Orsi RH, Wiedmann M. Characteristics and distribution of Listeria spp., including Listeria species newly described since 2009. Appl Microbiol Biotechnol. 2016;100:5273-87.

19. Hof H. An update on the medical management of listeriosis. Expert Opin Pharmacother. 2004;5:1727-35.

20. The European Union summary report on trends and sources of zoonoses, zoonotic agents and food-borne outbreaks in 2015. EFSA J. 2016;14:4634.

21. Scallan E, Hoekstra RM, Angulo FJ, Tauxe RV, Widdowson M-A, Roy SL, et al. Foodborne illness acquired in the United Statesmajor pathogens. Emerg Infect Dis. 2011;17:7-15.

22. Ivanek R, Grohn YT, Tauer LW, Wiedmann M. The cost and benefit of Listeria monocytogenes food safety measures. Crit Rev Food Sci Nutr. 2004;44:513-23.

23. Ben Slama R, Bekir K, Miladi H, Noumi A, Bakhrouf A. Adhesive ability and biofilm metabolic activity of Listeria monocytogenes strains before and after cold stress. Afr J Biotechnol. 2012;11: $12475-82$.
24. Carpentier B, Cerf O. Review - Persistence of Listeria monocytogenes in food industry equipment and premises. Int $\mathrm{J}$ Food Microbiol. 2011;145:1-8.

25. Melo J, Andrew PW, Faleiro ML. Listeria monocytogenes in cheese and the dairy environment remains a food safety challenge: the role of stress responses. Food Res Int. 2015;67:75-90.

26. Thevenot D, Dernburg A, Vernozy-Rozand C. An updated review of Listeria monocytogenes in the pork meat industry and its products. J Appl Microbiol. 2006;101:7-17.

27. Sivanesan A, Witkowska E, Adamkiewicz W, Dziewit L, Kaminska A, Waluk J. Nanostructured silver-gold bimetallic SERS substrates for selective identification of bacteria in human blood. Analyst. 2014;139:1037-43.

28. D'Agostino M, Wagner M, Vazquez-Boland JA, Kuchta T, Karpiskova R, Hoorfar J, et al. A validated PCR-based method to detect Listeria monocytogenes using raw milk as a food modeltowards an international standard. J Food Prot. 2004;67:1646-55.

29. Doumith M, Buchrieser C, Glaser P, Jacquet C, Martin P. Differentiation of the major Listeria monocytogenes serovars by multiplex PCR. J Clin Microbiol. 2004;42:3819-22.

30. Borucki MK, Call DR. Monocytogenes serotype identification by PCR. J Clin Microbiol. 2003;41:5537-40.

31. Mullapudi S, Siletzky RM, Kathariou S. Diverse cadmium resistance determinants in Listeria monocytogenes isolates from the Turkey processing plant environment. Appl Environ Microbiol. 2010;76:627-30.

32. Elhanafi D, Dutta V, Kathariou S. Genetic characterization of plasmid-associated benzalkonium chloride resistance determinants in a Listeria monocytogenes strain from the 1998-1999 outbreak. Appl Environ Microbiol. 2010;76:8231-8.

33. Mullapudi S, Siletzky RM, Kathariou S. Heavy-metal and benzalkonium chloride resistance of Listeria monocytogenes isolates from the environment of turkey-processing plants. Appl Environ Microbiol. 2008;74:1464-8.

34. Kaminska A, Kowalska A, Albrycht P, Witkowska E, Waluk J. $\mathrm{ABO}$ blood groups' antigen-antibody interactions studied using SERS spectroscopy: towards blood typing. Anal Methods. 2016;8:1463-72.

35. Liu D. Identification, subtyping, and virulence determination of Listeria monocytogenes, an important foodborne pathogen. J Med Microbiol. 2006;55:645-59.

36. Kathariou S. Listeria monocytogenes virulence and pathogenicity, a food safety perspective. J Food Prot. 2002;65:1811-29.

37. Ayaz ND, Erol I. Relation between serotype distribution and antibiotic resistance profiles of Listeria monocytogenes isolated from ground turkey. J Food Prot. 2010;73:967-72.

38. Wiedmann M, Bruce JL, Knorr R, Bodis M, Cole EM, McDowell CI, et al. Ribotype diversity of Listeria monocytogenes strains associated with outbreaks of listeriosis in ruminants. J Clin Microbiol. 1996;34:1086-90.

39. Jacquet C, Gouin E, Jeannel D, Cossart P, Rocourt J. Expression of ActA, Ami, InlB, and Listeriolysin $\mathrm{O}$ in Listeria monocytogenes of human and food origin. Appl Environ Microbiol. 2002;68:616-22.

40. Luna-Pineda T, Soto-Feliciano K, De La Cruz-Montoya E, Pacheco Londoño LC, Ríos-Velázquez C, Hernández-Rivera SP. Spectroscopic characterization of biological agents using FTIR, normal Raman and surface-enhanced Raman spectroscopies, 2007. p. $65540 \mathrm{~K}-65540 \mathrm{~K}-65511$

41. Demirel MC, Kao P, Malvadkar N, Wang H, Gong X, Poss M, et al. Bio-organism sensing via surface enhanced Raman spectroscopy on controlled metal/polymer nanostructured substrates. Biointerphases. 2009;4:35-41.

42. Premasiri WR, Lee JC, Sauer-Budge, Theberge R, Costello CE, Ziegler LD. The biochemical origins of the surface-enhanced Raman spectra of bacteria: a metabolomics profiling by SERS. Anal Bioanal Chem. 2016;408:4631-47. 
43. Webber MA, Piddock LJV. The importance of efflux pumps in bacterial antibiotic resistance. J Antimicrob Chemother. 2003;51: 9-11.

44. Dutta V, Elhanafi D, Kathariou S. Conservation and distribution of the benzalkonium chloride resistance cassette bcrABC in Listeria monocytogenes. Appl Environ Microbiol. 2013;79:6067-74.

45. Lebrun M, Audurier A, Cossart P. Plasmid-borne cadmium resistance genes in Listeria monocytogenes are similar to cadA and cadC of Staphylococcus aureus and are induced by cadmium. J Bacteriol. 1994;176:3040-8.

46. Wu CC, Gardarin A, Martel A, Mintz E, Guillain F, Catty P. The cadmium transport sites of CadA, the Cd2+-ATPase from Listeria monocytogenes. J Biol Chem. 2006;281:29533-41.

47. Bay DC, Rommens KL, Turner RJ. Small multidrug resistance proteins: a multidrug transporter family that continues to grow. Biochim Biophys Acta. 2008;1778:1814-38.

48. Liu Y, Zhou H, Hu Z, Yu G, Yang D, Zhao J. Label and labelfree based surface-enhanced Raman scattering for pathogen bacteria detection: a review. Biosens Bioelectron. 2017;94: 131-40.

49. Movasaghi Z, Rehman S, Rehman IU. Raman spectroscopy of biological tissues. Appl Spectrosc Rev. 2007;42:493-541.

50. Stone N, Kendall C, Smith J, Crow P, Barr H. Raman spectroscopy for identification of epithelial cancers. Faraday Discuss. 2004;126: 141-57. Discussion 169-183

51. Lau DP, Huang Z, Lui H, Man CS, Berean K, Morrison MD, et al. Raman spectroscopy for optical diagnosis in normal and cancerous tissue of the nasopharynx-preliminary findings. Lasers Surg Med. 2003;32:210-4.

52. Agranoff DD, Krishna S. Metal ion homeostasis and intracellular parasitism. Mol Microbiol. 1998;28:403-12.

53. Wu CC, Gardarin A, Catty P, Guillain F, Mintz E. CadA, the Cd2+ATPase from Listeria monocytogenes, can use $\mathrm{Cd} 2+$ as co-substrate. Biochimie. 2006;88:1687-92. 